\section{LA-8523-MS}

Informal Report of

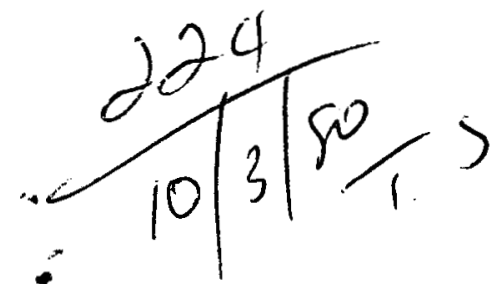

Dr. 1804

Future Credible Precipitation Occurrences in Los Alamos, New Mexico

$\frac{\frac{\sigma}{C}}{\frac{0}{0}}$

to

$\frac{7}{\omega}$

$\stackrel{\frac{2}{5}}{\frac{2}{5}}$ 


\section{DISCLAIMER}

This report was prepared as an account of work sponsored by an agency of the United States Government. Neither the United States Government nor any agency Thereof, nor any of their employees, makes any warranty, express or implied, or assumes any legal liability or responsibility for the accuracy, completeness, or usefulness of any information, apparatus, product, or process disclosed, or represents that its use would not infringe privately owned rights. Reference herein to any specific commercial product, process, or service by trade name, trademark, manufacturer, or otherwise does not necessarily constitute or imply its endorsement, recommendation, or favoring by the United States Government or any agency thereof. The views and opinions of authors expressed herein do not necessarily state or reflect those of the United States Government or any agency thereof. 


\section{DISCLAIMER}

Portions of this document may be illegible in electronic image products. Images are produced from the best available original document. 


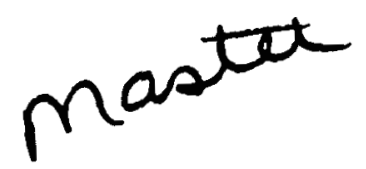

LA-8523.MS

Informal Report

UC-11

Issued: September 1980

\title{
Future Credible Precipitation \\ Occurrences in Los Alamos, New Mexico
}

\author{
W. V. Abeele
}

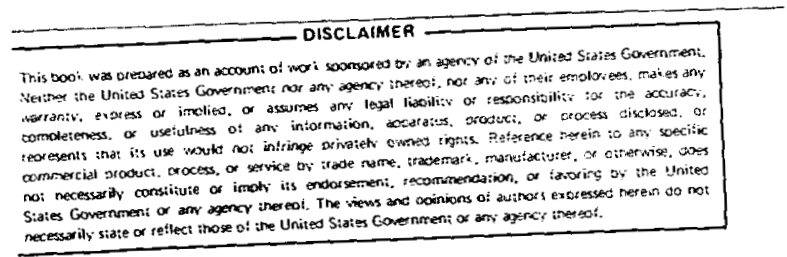

DISTRIBUTION OF THIS GOCUHEFT IS UNLINUTED 


\title{
FUTURE CREDIBLE PRECIPITATION OCCURRENCES IN LOS ALAMOS, NEW MEXICO
}

\author{
by
}

\author{
W. V. Abeele
}

\begin{abstract}
I have studied many factors thought to have influenced past climatic change. Because they might recur, they are possible suspects for future climatic alterations. Most of these factors are totally unpredictable; therefore, they cast a shadow on the validity of derived climatic predictions. Changes in atmospheric conditions and in continental surfaces, variations in solar radiation, and in the earth's orbit around the sun are among the influential mechanisms investigated. Even when models are set up that include the above parameters, their reliability will depend on unpredictable variables totally alien to the model (like volcanic eruptions).

Based on climatic records, however, maximum precipitation amounts have been calculated for different probability levels. These seem to correspond well to past precipitation occurrences, derived from tree ring indices. The link between tree ring indices and local climate has been established through regression analysis.
\end{abstract}

\section{INTRODUCTION}

The ability to predict maximum credible precipitation occurrences would be of paramount importance for the estimation of probable moisture content and subsequent hydraulic conductivity in tuff. ${ }^{1}$ The values of hydraulic conductivity are im. portant for estimating radionuclide movement in tuff surrounding waste pits.

Prediction of minimum credible precipitation occurrences may be useful in estimating the looseness of soil particles and lowering of the roughness height because of a restriction in vegetation growth resulting from drought conditions. Both of the above factors will be very effective in influencing wind erosion.

\section{SELECTED METHODS}

Three different approaches were selected to predict future climate trends in Los Alamos, New Mexico.

1. The study of several factors thought to have influenced past climatic changes and which, because they might recur, are possible suspects for future climate alterations. Many of the above factors are totally unpredictable and consequently cast a shadow on the validity of derived climatic predictions.

2. A look at possible correlations between tree ring indices and past climatological events. The study 
of past climatic trends may be an indication of what extremes in climate may be expected in the near future.

3. Consulting the climatological data gathered at Los Alamos from 1951 to the present (last $30 \mathrm{yr}$ ), precipitation amounts at different levels of probabilities can be predicted. This classic approach assumes that none of the alleged disruptive factors, considered in the first case, cause the future climate to shift.

\section{PAST Climates}

Paleoclimatology involves the study of relations between lithogenetic and climatic factors. A hot and humid climate is linked to intensive chemical weathering of rocks, while in a cold and dry climate, physical weathering will predominate. In a hot and dry climate, neither chemical nor physical weathering may prevail. Alluvial deposits are linked to an excess of precipitation, which will also affect the water inflow into a land-locked reservoir. A variation of inflow will be recorded as a level oscillation. It has further been found that the ratio of $\mathrm{O}^{18}$ to $\mathrm{O}^{16}$ in fossil remains is an indication of the temperature experienced by aquatic animals during their lifetime. ${ }^{2}$ It is generally assumed that the precipitation in subhumid areas dropped to even lower levels during warming trends. This is probably due to a poleward shift of the climatic zones. The subtropical high pressure belt widened, resulting in the poleward expansion of arid areas. Because of the expansion of the tropical belt, however, precipitation increased in what is now the dry subtropical belt of high pressure.

Cooling brought about the formation of glaciers. Their advance and recession was almost synchronous throughout the world, bringing about changes of $150 \mathrm{~m}$ in sea level. The climax of glaciation was an apparent trigger for a decrease in precipitation over adjacent continents, due to a reduction in evaporation over the glaciated oceans. ${ }^{2}$ This precipitation decrease brought about starvation of glaciers.

\section{A. Changes in Atmospheric Composition}

Two components of the atmosphere, carbon dioxide and aerosols of volcanic origin, are given special attention because of their direct climatic implications.

Carbon dioxide is an outstanding absorber of longwave terrestrial radiation. Water vapor absorbs even more longwave terrestrial radiation than carbon dioxide in the present concentrations. An eventual increase of carbon dioxide in the atmosphere will cause an increase in the earth's surface temperature, thereby raising the potential absolute humidity. The increased concentration of water vapor, linked to an increased concentration of carbon dioxide, may lead to further increases in temperature.

A certain amount of carbon dioxide enters the atmosphere during volcanic eruptions. It has long been assumed that in past eras (Paleozoic, Mesozoic), the atmosphere contained a much greater amount of carbon dioxide $(0.1$ to $0.4 \%)$ than at present $(0.032 \%)$. It is possible to explain the reduction in carbon dioxide concentration in the atmosphere by a decrease in volcanic activity. ${ }^{3}$ Arrhenius ${ }^{4}$ estimated that a 2.5- to 3-fold increase in carbon dioxide raised the air temperature by 8 to $9^{\circ} \mathrm{C}$, while a decrease of 38 to $45 \%$ lowers the temperature by 4 to $5^{\circ} \mathrm{C}$. Manabe and Wetherald ${ }^{3}$ came to the conclusion that, for constant relative humidity, temperature variations caused by a doubling of carbon dioxide concentrations amounted to an increase in air temperature of $2.4^{\circ} \mathrm{C}$.

The cyclic nature of glaciation has been attributed to an initial decrease of carbon dioxide in the air, followed by a temperature drop, resulting in the growth of glaciers, in turn initiating a reduction of liquid ocean water, thereby reducing the amount of carbon dioxide in solution. The subsequent increase in atmospheric carbon dioxide leads to a new warming. ${ }^{3}$ This theory is far from universally accepted, on the ground that

1. The solubility of carbon dioxide increases with a decrease in water temperature. This may counter-balance the decrease in volume of ocean water.

2. Glaciation is a self-generating process. The greater the glaciated area, the greater the albedo of the earth and the greater the cooling process. According to this widely held view, the prospect of total glaciation is a very real one. ${ }^{2}$ 
Despite the preceding statements linking the cyclic nature of glaciation to cyclic variations of carbon dioxide in the atmosphere, the origin of the Ice Ages remains one of the most stubborn mysteries in paleoclimatology. Attempts at correlating the Ice Ages with carbon dioxide concentrations are only a few among the more than 600 that have been proposed as theories of continental glaciation. ${ }^{\circ}$

The quantitative effect of atmospheric aerosol on the climate is still a subject of controversy. Radiational increases are often considered to be the result of volcanic aerosols being cleared from the atmosphere.

$\mathrm{Karol}^{7}$ asserts that if the source of aerosols is outside the tropics, the aerosols will spread quickly over the hemisphere of origin and slowly to the other hemisphere. If the aerosol source is in the equatorial zone, it spreads equally over both hemispheres.

The warming that peaked in the 1940s may be possibly due to an increase in solar radiation reaching the earth's surface, which may have resulted from an increase in the transparency of the stratosphere. A decrease in transparency will obviously be at the origin of a cooling trend. Brooks ${ }^{8,8}$ estimates that increased volcanism served as a contributary cause to continental glaciation, but no more than that.

$\mathrm{Lamb}^{10}$ on the other hand, is of the opinion that volcanism is a major factor regulating the climate. His studies attempt to explain the increased glaciation that followed volcanic eruptions since 1500 . Wexler ${ }^{11}$ believed that since the specific heat of continents is much lower than that of oceans, they cool much more rapidly than oceans if submitted to a reduction in radiation intensity from volcanic activity. This increased temperature contrast would create a winter condition favorable to continental glaciation. Sellers ${ }^{12}$ believes also that volcanism could be a possible trigger for glaciation due to a large drop of direct radiation occurring mainly in winter, which would indicate dependency on atmospheric transparency and not a fluctuation in the solar. constant.

\section{B. Changes in Continental Surfaces}

Brooks $^{8,9}$ estimates that a restriction in oceanic circulation between low and high latitudes must have been at the origin of polar ice formation. An unrestricted circulation might mean a polar rise in temperature of the order of $6^{\circ} \mathrm{C}-$ more than enough to keep the Arctic free of ice.

Albrecht ${ }^{13}$ advanced the theory that meridional mountain formations were blocking atmospheric circulation to the extent that a decrease in winter precipitation resulted, lowering the inflow of condensation heat and consequently contributing to the cooling of the middle and high latitudes. This seems to be in contradiction to the widely held view that a low solid precipitation is inhibitive to the formation of glaciers!

Others ${ }^{14}$ are of the opinion that underwater ridges in the North Atlantic blocked oceanic heat transfer resulting in the Quaternary glaciations.

Plate tectonics suffered some drawbacks, but has many persuasive features as a probable cause for climatic change. That assumption seems to be gaining new ground as a cause for long-term climatic changes. It is not only verified by observation, but can also be used to explain the change in climate distribution without any net heating or cooling of the earth as a whole. Vast ice sheets are known to have existed in the tropical regions of Africa, Australia, and South America. Brooks ${ }^{8,8}$ puts the temperature of the region north of $40^{\circ} \mathrm{N}$ during most of the late Cambrian at about $15^{\circ} \mathrm{C}$. During this period, the equator probably passed through the United States, Greenland, and western Asia. ${ }^{12}$ Some proponents of climatic change through plate tectonics visualize movements which may reach $0.5 \mathrm{~m} \mathrm{a}$ year. ${ }^{12}$ Runcorn ${ }^{15}$ explains continental drift by suggesting that the heat flow out of the earth's core produced thermal convective currents, causing the continents to move toward regions where the currents are descending. Runcorn's geophysical theory of continental drift fails to explain the short glacial epochs.

\section{Variations in Solar Radiation}

Several researchers came to the conclusion that the solar constant increases during average solar activity periods and decreases during low and high activity periods. Simpson ${ }^{16}$ advances a theory based on 380000 year long cycles of the solar constant. He argues that minimal increases of the solar constant bring about a stronger latitudinal temperature gradient, because of higher temperature increases at 
the equator. This would strengthen atmospheric circulation and evaporation. The acceptance of this theory would compel one to believe that extremely wet interglacial periods occurred. This cannot be verified geologically. Wetherald and Manabe ${ }^{17}$ determined, on the other hand, that a $2 \%$ increase of the solar constant would lead to a $2^{\circ} \mathrm{C}$ increase of the annual air temperature at low latitudes and to as much as a $10^{\circ} \mathrm{C}$ increase at $80^{\circ}$ latitude because of partial melting of the pack-ice in the polar ocean! A $4 \%$ decrease of the solar constant would lead to complete glaciation. A direct correlation has been found since the end of the 19th century, when actinometric observations were first documented, between temperature variations and radiation reaching the earth's surface. However, the National Academy of Sciences ${ }^{18}$ acknowledges that "nobody has measured the solar constant to better than 1 to 2 percent!" Wellett ${ }^{10}$ suggests that climatic cycles are caused mainly by sunspot disturbances, which bring about radiational perturbations that act directly on the upper atmosphere. It is assumed that these disturbances modify the circulation pattern, thereby. producing climatic modifications. Sunspot disturbances have cyclic variations of 22 (double sunspot cycle) and 80 years. Wellett ${ }^{18}$ demonstrates that periods of low sunspot activity, occurring from 1800 to 1820 and from 1880 to 1900 in the 80 year cycle, are related to periods of glacial advance. That hypothesis remains primarily a statistical one and, as such, is subject to widespread criticism.

\section{Variations in the Earth's Orbit Around the Sun}

1. The obliquity of the ecliptic varies cyclically 1.5 degrees about a mean of 23.1 degrees over a period of 40000 years. ${ }^{12}$ A large obliquity would produce a great seasonal contrast. A lack of obliquity would result in an annually homogeneous climate.

2. The eccentricity of the earth's orbit varies cyclically over a period of 97000 years. As a result of the eccentricity of the earth's orbit, the hemisphere that is closest to the sun in the winter will have a tendency to have mild winters and summers. This effect will be most pronounced when the eccentricity is at its peak. The difference between the aphelion and perhelion, divided by the semi-major axis of revolution, presently is 0.0334 . According to the radiation law that states that radiation intensity decreases with the square of the distance from the source, the annual fluctuation for the solar constant is currently 0.068 . Because the earth is presently closest to the sun during the northern hemisphere winters, the seasons should be milder in the northern hemisphere. This is counter balanced, however, by the presence of a bigger oceanic mass in the southern hemisphere. The ocean has a mitigating effect on seasonal extremes. The influence of orbital changes on climatic fluctuations is widely accepted, because it is known that they are cyclical, whereas long term variations of the solar constant are highly speculative. ${ }^{20}$

\section{E. Contemporary Changes in Precipitation}

The consensus is that when the average temperature rises, the latitudinal temperature gradient drops (contrary to Simpson' ${ }^{16}$ assertion) and there is tendency toward a decrease in precipitation in regions of unstable moisture (temperature latitudes). It can consequently be assumed that, through atmospheric circulation, the latitudinal temperature gradient controls, to a large extent, precipitation variations. These variations in precipitation are best recorded in the fluctuations of the Caspian Sea level. The decrease in precipitation was reflected in the drastic drop of its level in the 1930s. The low levels in the Caspian Sea correlate well with low crop yields obtained in the United States during the same period. This seems to reinforce the theory that this precipitation change mechanism is triggered by a universal cause-a decrease in latitudinal temperature gradient caused by a general warming trend. ${ }^{2}$ As the result of an increased temperature gradient, the intensity of zonal transfer can be expected to increase also, adding to the subsequent continental precipitation.

\section{CLIMATES OF THE FU'TURE}

"...when somebody asks me what I think about the future climate, I usually say that the best way of showing that you are not a capable climatologist is to try to make a forecast"-

Bert Bolin, 1976 
This view coincides closely with the official position, of the American Meteorological Society. ${ }^{21}$ Climatic forecasts are often based on what Gani ${ }^{22}$ has referred to as "poor foundations, apparent similarities, parallel-looking curves and analogous trends." Models that include interactions between the atmosphere-ocean-polar ice cap system responsible for climatic change on various time scales do not exist as of the date of the study sponsored by the National Academy of Sciences. ${ }^{18}$ Even when the models do exist, their reliability hinges on factors totally external to the model, such as volcanic eruptions and solar radiation fluctuations.

Taking climatic records and looking for past trends to forecast future events without a physical understanding of the underlying mechanisms that triggered past trends, often leads to erroneous results. Even an understanding of these mechanisms would have failed if the existing temperature in the 1940 s had been projected. ${ }^{18}$

For the first time, however, mankind has the power to bring about a fluctuation in one of the factors known to influence climate-carbon dioxide. Quantitatively, its impact is still a hotly debated issue. Some models have predicted increases in temperature on the order of a few tenths of a degree because of the increase in carbon dioxide since 1900 . Because the temperature in the northern hemisphere has decreased since 1945 , even though carbon dioxide increased exponentially, the validity of the carbon dioxide theory could be brought into doubt. ${ }^{18}$

The N.A.S. study ${ }^{18}$ made in 1977 concludes that theory is yet unable to predict future climates, so an analysis of recent past records is probably the best quantitative way to estimate the range of future variability. Because recent past records are available for the area either in the form of direct climatic records, or as tree ring indices, both of these will be the subject of further investigations.

\section{RECENT CLIMATIC RECORDS}

Based on updated climatic records (1951 to 1980) for Los Alamos, New Mexico, precipitation equal to or less than an expected amount has been calculated for probability levels of 0.01 to 0.99 . These values were determined based on the normal distribution obtained from climatic precipitation data recorded in the last 30 years. Table I indicates those values on a yearly basis. By reading Table $I$, one can notice that there is a 0.95 chance that the annual precipitation is less than $698 \mathrm{~mm}$. It can also be interpreted that there will be a 0.05 chance that the annual precipitation will exceed $698 \mathrm{~mm}$. Separate computations show that during the last five years a trend has developed whereby the precipitation variability in January, February, April, May, September, and November has increased, whereas it decreased during the remaining months and on an annual basis. The updated (1980) mean annual precipitation is $457 \mathrm{~mm}$ for Los Alamos.

\section{TREE-RING EVIDENCE}

The climatic information in tree rings can be analyzed to give an idea of what past climates were like and what they possibly will be like in the near future. The aspect of science more particularly concerned in reconstructing climates by use of tree ring indices is known as dendroclimatology. This involves comparing modern meteorological records with contemporaneous tree ring widths and establishing, through regression analysis, the best statistical relationship existing between the tree ring index as the independent variable and, say, precipitation as the dependent variable. By then substituting tree ring indices in the equation, one obtains an estimate of previous precipitation patterns. Regions, where temperature or rainfall is a severely limiting factor in growth, yield the most

TABLE I

UPDATED PRECIPITATION WITH PROBABILITY EQUAL TO OR LESS THAN (mm)

$\begin{array}{lccccccccccccc}\text { Level } & 0.01 & 0.05 & 0.10 & 0.20 & 0.30 & 0.40 & 0.50 & 0.60 & 0.70 & 0.80 & 0.90 & 0.95 & 0.99 \\ \text { Ppt } & 146 & 216 & 259 & 303 & 333 & 356 & 457 & 558 & 581 & 611 & 655 & 698 & 768\end{array}$


clearly interpretable climatic indices. In Los Alamos, the one factor that can be notably limiting is precipitation. This should stimulate backward extension of precipitation gage records by growth indices. Throughout the western United States, the University of Arizona has supported a continuing search for the most sensitive trees, a fundamental phase of a research program with its main objective the derivation of centuries-long rainfall indices of quantitative value. No other region in the world is apparently so naturally favored as a source of dendroclimatic history.$^{23}$ Long-lived coniferous species, with abilities to survive very arid cycles, make selective studies possible. Tree ring indices have been obtained that showed a high dependency on annual rainfall.

In Los Alamos, the best correlations between tree ring indices and annual precipitation were found for (in order of goodness of fit):

1. Ponderosa pines, where precipitation $(\mathrm{mm})=543$ $\mathrm{I}_{\mathrm{PO}}^{0.608}$ The corresponding correlation coefficient was found to be significant at the 0.99 level $\left(\mathrm{I}_{\mathrm{Po}}\right.$ tree ring index for ponderosa pine).

2. Piñon, where precipitation $(\mathrm{mm})=467 \mathrm{I}_{\mathrm{P} 1}^{0,819}$; the correlation coefficient in this case was found to be still significant at the 0.99 level $\left(\mathrm{I}_{\mathrm{p}^{\prime}}=\right.$ tree ring index for piñon).

The similarity between these two equations is striking. The fact that in both cases the exponent of the index is $<1$ indicates that relatively small increases in precipitation could lead to sizeable increases of tree ring indices in the Los Alamos area. A $100 \%$ increase of the index (doubling) corresponds to a $50 \%$ increase in precipitation, while a $50 \%$ decrease of the index (halving) represents a $33 \%$ decrease in precipitation.

The comparison between modern meteorological records and contemporaneous tree ring indices involves only the last 30 years. The mean tree ring index of 1 , on the other hand, is based on records dating back to 1510 for ponderosa pine. If we substitute the mean tree ring index of 1 in the above formulae, a precipitation is obtained that is higher than the mean precipitation recorded during the last 30 years, because of a coefficient (543, e.g.) whose value exceeds the actual mean precipitation. This higher coefficient is because, during the thirty years to which the regression analysis was applied, the tree ring index was below the average or $<1$. This also implies that during the period in question, precipitation was below average since 1510 .

\section{CONCLUSIONS}

Reliable models that include interactions between the atmosphere-ocean-polar ice cap system responsible for climatic change on various time scales do not exist. Models taking into account changes in atmospheric conditions and continental surfaces, variations in solar radiation, and the earth's orbit around the sun can be upset by factors totally alien to the model.

There is a need though to point out the cyclical nature of glacial and interglacial epochs. We currently are about 10000 years into a warm interglacial epoch. Some interglacial periods only last this long!

Anthropogenically-induced carbon dioxide and its related heating effect are undoubtedly the main contemporary climatological problems that could very well upset the cyclical nature of glaciation. ${ }^{24}$

There seems to be agreement, however, that an analysis of recent past records, in the form of either climatic records or tree ring indices, is the best way to estimate the range of future pluvial variability.

The statistical relationship established between modern pluviometric records and contemporaneous tree ring indices allows one to estimate previous precipitation patterns. Good existing correlations for ponderosa pine permitted us to make the following estimates.

1. In the last 100 years, a maximum tree ring index of 1.85 occurred in 1919. Through regression analysis and use of derived formulae, one is able to compute that this corresponds to an annual precipitation of $788 \mathrm{~mm}$.

2. In the last 200 years a maximum tree ring index of 2.10 occurred in 1794 . Through regression analysis and use of derived formulae, one is able to compute that this corresponds to an annual precipitation of $851 \mathrm{~mm}$.

3. The maximum tree ring index recorded in the Los Alamos area was 2.80 in 1597 . This corresponds to 
an annual precipitation of $1013 \mathrm{~mm}$. Derived maximum annual precipitations are summarized in Table II.

\section{TABLE II}

\section{ANNUAL PRECIPITATION ESTIMATES DERIVED FROM TREE RING INDICES}

\begin{tabular}{|c|c|c|}
\hline $\begin{array}{l}\text { Time } \\
\text { Period }\end{array}$ & $\begin{array}{l}\text { Maximum } \\
\text { Tree Ring }\end{array}$ & $\begin{array}{l}\text { Derived Annual } \\
\text { Precipitation }\end{array}$ \\
\hline 100 & 1.85 & 788 \\
\hline 200 & 2.10 & 851 \\
\hline 500 & 2.80 & 1013 \\
\hline
\end{tabular}

4. The minimum tree indices recorded were in the years $1523,1524,1585$, and 1685 . According to the regression equation, this corresponds to annual precipitations of $144,144,113$, and $58 \mathrm{~mm}$, respectively. Statistics based on pluviometric records indicate that annual precipitation not exceeding $146 \mathrm{~mm}$ is likely to occur once in 100 years.

The above precipitation estimate correspond remarkably well with the estimated occurrences of maximum precipitation based on climatic records. Table I indicates that a maximum precipitation of $768 \mathrm{~mm}$ can be expected every century. This is only $2.5 \%$ different from the estimate reached by tree ring index analysis.

\section{REFERENCES}

1. W. V. Abeele, "Determination of Hydraulic Conducitivity in Crushed Bandelier Tuff," Los Alamos Scientific Laboratory report LA-8147-MS (1979).

2. M. I. Budyko, "Climatic Changes," Translation from Russian, American Geophysical Union, Washington, D.C., 261 pp (1977).

3. M. I. Budyko, "The Heat Balance of the Earth," in Climate Change, J. Gribbin, Ed., pp. 85-113, Cambridge University Press, New York (1978).
4. S. Arrhenius, "Lehrbuch de Kosmischen Physik," Herzel, Leipzig, 1026 S. (1903).

5. S. Manabe and R. T. Wetherald, "Thermal Equilibrium of the Atmosphere with a Given Distribution of Relative Humidity," J. Atmos. Sci., 24, 241-259 (1967).

6. L. E. Long, Geology, McGraw-Hill Book Company, New York (1974).

7. 1. L. Karol, "Radioactive Isotopes and Global Transfer in the Atmosphere," (in Russian), 365 pp., Gidrometeoizdat, Leningrad (1972).

8. C.E.P. Brooks, "Climate Through the Ages," Second Edition, Ernst Benn, London (1950).

9. C.E.P. Brooks, "Geological and Historical Aspects of Climatic Change," pp. 1004-1018 in Compendium of Meteorology, American Meteorological Society, Boston (1951).

10. H. H. Lamb, "Volcanic Dust in the Atmosphere," Phil. Trans., Roy Soc. of London, Appl. Math. Phys. Sci., 226, 1178, 425-533 (1970).

11. H. Wexler, "Possible Causes of Climatic Fluctuations," in Dynamics of Climate, pp. 93-95, Pergamon Press, New York (1960).

12. W. D. Sellers, Physical Climatology, The University of Chicago Press, Chicago (1965).

13. F. Albrecht, "Aktiongebiete des Wasser-und Wärmehaushaltes der Erdoberfläche," Z. Meteorol., 1, 4-5, 97-109 (1947).

14. D. M. Ewing and W. L. Donn, "A Theory of Ice Ages, II," Science, 127,1159-1162 (1958).

15. S. K. Runcorn, "Paleomagnetic Evidence for Continental Drift and its Geophysical Cause," in Continental Drift," pp. 1-40, Academic Press, New York (1962).

16. G. C. Simpson, "World Temperatures During the Pleistocene," Quart. J. Roy. Meteorol. Soc., 85:332-49 (1959). 


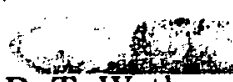

17. R. T. Wetherald and S. Manabe, "The Effect of Changing the Solar Constant on the Climate of a General Circulation Model," J. Atmos. Sci., 32, 11, 2044-2059 (1975).

18. "Climate, Climatic Changes and Water Supply," the National Academy of Sciences, Washington, D.C., $132 \mathrm{pp}$ (1977).

19. H. C. Willet, "Evidence of Solar-Climatic Relationships," in Weather and Our Food Supply, Iowa State University, Ames, pp. 123-51 (1964).

20. H. A. Panofsky, "Theories of Climatic Change," Weatherwise, 9:183-87, 204 (1956).
21. Policy statement of the American Meteorological Society on weather forecasting, Bull. Am. Meteorol. Soc., 54, 1 (1973).

22. J. Gani, "The Use of Statistics in Climatological Research," Search 6, Nos. 11-12 (1975).

23. E. Schulman, "Tree-Ring Indices of Rainfall, Temperature, and River Flow," Compendium of Meteorology (American Meteorological Society, Boston, 1951), pp. 1024-1029. See also Tree-Ring Bulletin 18, 10-18 (1952).

24. F. Hare, "Climate and Agriculture: The Uncertain Future," J. of Soil and Water Conservation, Vol. 35, No. 3, pp. 112-115 (1980). 